\title{
Distribution and Determinants of Low Birth Weight in Developing Countries
}

\author{
Rashidul Alam Mahumud', Marufa Sultana ', Abdur Razzaque Sarker ${ }^{1,2}$ \\ ${ }^{1}$ Health Economics and Financing Research, Health Systems and Population Studies Division, International Centre for Diarrhoeal Disease Research, \\ Bangladesh (icddr,b), Dhaka, Bangladesh; ${ }^{2}$ Department of Management Science, University of Strathclyde, Glasgow, United Kingdom
}

Objectives: Low birth weight (LBW) is a major public health concern, especially in developing countries, and is frequently related to child morbidity and mortality. This study aimed to identify key determinants that influence the prevalence of LBW in selected developing countries.

Methods: Secondary data analysis was conducted using 10 recent Demography and Health Surveys from developing countries based on the availability of the required information for the years 2010 to 2013. Associations of demographic, socioeconomic, communitybased, and individual factors of the mother with LBW in infants were evaluated using multivariate logistic regression analysis.

Results: The overall prevalence of LBW in the study countries was $15.9 \%$ (range, 9.0 to $35.1 \%$ ). The following factors were shown to have a significant association with the risk of having an LBW infant in developing countries: maternal age of 35 to 49 years (adjusted odds ratio [aOR], 1.7; 95\% confidence interval [Cl], 1.2 to $3.1 ; p<0.01)$, inadequate antenatal care (ANC) (aOR, 1.7; $95 \% \mathrm{Cl}, 1.1$ to 2.8 ; $p<0.01$ ), illiteracy (aOR, 1.5; $95 \% \mathrm{Cl}, 1.1$ to $2.7 ; p<0.001$ ), delayed conception ( $\mathrm{aOR}, 1.8 ; 95 \% \mathrm{Cl}, 1.4$ to $2.5 ; p<0.001$ ), low body mass index (aOR, 1.6; $95 \% \mathrm{Cl}, 1.2$ to $2.1 ; p<0.001)$ and being in the poorest socioeconomic stratum (aOR, $1.4 ; 95 \% \mathrm{Cl}, 1.1$ to $1.8 ; p<0.001$ ). Conclusions: This study demonstrated that delayed conception, advanced maternal age, and inadequate ANC visits had independent effects on the prevalence of LBW. Strategies should be implemented based on these findings with the goal of developing policy options for improving the overall maternal health status in developing countries.

Key words: Developing countries, Global health, Low birth weight, Odds ratio

\section{INTRODUCTION}

Infant birth weight is a significant predictor of the immediate and future health status of a newborn. Low birth weight

Received: September 19, 2016, Accepted: December 19, 2016

Corresponding author: Rashidul Alam Mahumud, MSc 68 Shaheed Tajuddin Ahmed Sarani, Mohakhali, Dhaka, Bangladesh

Tel: +880-2-9827001-10, Fax: +880-2-8811568

E-mail: rashidul.alam@icddrb.org

This is an Open Access article distributed under the terms of the Creative Commons Attribution Non-Commercial License (http://creativecommons.org/licenses/by$\mathrm{nc} / 4.0 /$ ) which permits unrestricted non-commercial use, distribution, and reproduction in any medium, provided the original work is properly cited.
(LBW) is a major public health concern and one of the strongest single risk factors for early neonatal mortality and morbidity $[1,2]$. According to the World Health Organization, the prevalence of LBW is $15.5 \%$ globally, and $96.5 \%$ of LBW infants are born in developing countries [3,4]. LBW has been defined as a birth weight of less than $2500 \mathrm{~g}$ regardless of gestational age. Consequently, LBW is considered to be associated with a greater risk of early childhood death than is associated with normal birth weight [5]. Furthermore, it is a significant factor associated with higher probabilities of infection, greater susceptibility to childhood illness, lower chances of child survival, long-term physical and mental deficiencies, and problems related to behavior, learning, and psychosocial improvements 
during childhood $[2,6]$. In the perinatal period, LBW infants are in a critical state with regard to survival, and approximately half of all neonatal deaths are directly or indirectly linked to LBW [7]. This adverse pregnancy outcome may be influenced by several conditions, such as heart disease, diabetes, hypertension, behavioral disorders, impaired cognitive function, psychological disorders, and a substantial risk of complications related to the stoma includes the esophagus, stomach, duodenum, ileum, colon, pleural cavity, ureters, urinary bladder, and kidney pelvis etc. [8], and usually incurs long-term financial burdens for households $[9,10]$. Furthermore, with the demographic change of increased life expectancy at birth in developing countries, children born with LBW can cause an increased economic burden and an increased disease burden $[10,11]$. Consequently, LBW is considered as a universal threat for developing countries that creates a barrier for child development $[12,13]$. Previous studies have shown several factors to be determinants of LBW and have demonstrated that preventing those factors can help reduce early childhood morbidity and mortality [14]. The determinants of LBW can be broadly classified as genetic, constitutional, obstetric, nutritional, related to maternal morbidities in the antenatal period, toxic exposure-related, and linked to antenatal care (ANC). Other factors including smoking, maternal age, birth spacing, ANC, anemia, genital infections, maternal ill health, and stress have also been reported [15]. Research on the prevalence and determinants of LBW has been conducted using nationwide population-based survey data, with some studies focusing on developing countries. However, most of the multi-country studies were conducted using recalled birth weight data, with mothers reporting information about the size of their newborn baby (e.g., very small, small, normal, large, and very large) from memory, which may have affected the accuracy of the results regarding LBW [16]. This study used a continuous type of birth weight data derived from Demography and Health Surveys (DHSs) among 10 selected developing countries. However, global development has entered a new era, as world leaders have evaluated the achievements of the Millennium Development Goals and adopted the 2030 Agenda for Sustainable Development in the name of Sustainable Development Goals (SDGs). The specific SDGs known as the health goal (goal No. 3) aims to "ensure healthy lives and promote well-being for all at all ages," with one of the important targets being to ensure universal access to reproductive health care services, including family planning, information and educa- tion, and the integration of reproductive health into national strategies and programs. The aim of this study was to investigate the distribution and determinants of LBW in selected developing countries so that policy makers in all countries can design effective plans for building stronger communities, emphasizing a comprehensive approach to reach their objectives, particularly SDG-3.

\section{METHODS}

\section{Study Design}

Secondary data analysis was carried out using DHS data for the period of 2010 to 2013 from the following least-developed countries as defined by the World Bank: US (2010), Cambodia (2010), Colombia (2010), Indonesia (2012), Jordan (2012), Nepal (2011), Pakistan (2012-2013), Tanzania (2010), Uganda (2011), and Zimbabwe (2010-2011). Moreover, those surveys used continuous of birth weight data, which was another criterion for choosing those countries.

\section{Data Collection and Sampling Technique}

The DHS collected national-level household-based survey data on birth weight retrospectively from mothers whose youngest child was under five years of age. The DHS used a stratified, two-stage cluster sampling design. The first stage involved selecting samples from a master sampling frame constructed from enumeration, and the second stage involved systematic sampling of the households listed from each cluster, to ensure that adequate numbers of completed individual interviews were obtained. The survey collected data through questionnaire-based face-to-face interviews, for which women of reproductive age (15 to 49 years) were interviewed based on the Measure DHS program model. Each respondent (mother) was asked to provide a detailed birth history for births in the preceding survey. Birth weight was recorded using the metric scale (in grams) in all selected study countries. Details regarding the sample design, specific consent, and data collection procedures have been reported elsewhere, in the DHS reports from the individual countries [17].

\section{Outcome Variable}

The DHS recorded birth weight data from mothers whose youngest child was less than five years old in the five years preceding the survey using health card records. Entries on health cards were generally completed by a physician or a 
health worker and given to mothers upon discharge from the health facility (e.g., hospital, clinic or any other healthcare institution). Reporting birth weight information on health cards has been found to be more reliable than obtaining birth weight information through maternal recall [18]. The birth weight information derived from the DHS may include possible misclassifications, as the DHS used the proxy variable of the reported size of the infant at birth, which may lead to potential heaping [18-21]. This study analyzed only the numerical birth weight data contained in the DHS survey for only the most recent children. Finally, birth weight data were classified into two groups: non-LBW (birth weight $\geq 2500 \mathrm{~g}$ ) or LBW (birth weight $<2500 \mathrm{~g}$ ). Data from children with a missing birth weight, mothers with twin or multiple pregnancies, and stillbirths were excluded from the analysis.

\section{Independent Variables}

The study variables were selected based on epidemiological information, prior studies, a review of the relevant published demographic studies, and the available information in the DHS datasets, with a consideration of potential confounders [22-24]. Individual-level factors such as maternal age, the height of the mother, sex of the child, educational status, occupational status, parity, ANC visits, intake of iron during pregnancy, maternal hemoglobin $(\mathrm{Hb})$ levels, and nutritional status, as well as community-level factors, such as wealth status and place of residence, were considered in the study. Maternal age was divided into the categories of $\leq 19$ years, 20-34 years, and 35-49 years, and maternal height was defined as short $(\leq 145 \mathrm{~cm})$, average $(146-155 \mathrm{~cm})$, or tall $(>155 \mathrm{~cm})$. The sex of the child was recorded as male or female. Education level was defined as no education, primary education, or secondary or higher education, and current occupational status was classified as not working or working. Frequency of ANC visits was defined as inadequate ( 0 or 1$)$, intermediate ( 2 or 3 ), or adequate (4 or more), and parity was classified as first birth, 2-3 births, 4 or more births. Age at first cohabitation was defined as $\leq 12$ years, $13-17$ years, or $\geq 18$ years. Whether the mother had taken iron pills during pregnancy was recorded as yes or no. Maternal $\mathrm{Hb}$ levels were measured using the HemoCue (HemoCue, Angelholm, Sweden) rapid testing method, and participants were divided based on whether their $\mathrm{Hb}$ level was $<12.0 \mathrm{~g} / \mathrm{dL}$ or $\geq 12.0 \mathrm{~g} / \mathrm{dL}$. Height and body weight were obtained from the dataset, and body mass index (BMI) was calculated as the ratio of weight in kilograms to height in meters squared $\left(\mathrm{kg} / \mathrm{m}^{2}\right)$. BMI was further categorized into three groups: low $\left(\leq 18.5 \mathrm{~kg} / \mathrm{m}^{2}\right)$, normal or healthy weight (18.5$24.9 \mathrm{~kg} / \mathrm{m}^{2}$ ) or overweight $\left(\mathrm{BMI}>24.9 \mathrm{~kg} / \mathrm{m}^{2}\right)$. The DHS applied an asset-based approach to estimate household wealth status, which was measured based on the ownership of durable assets. Each variable (asset) was dichotomized as 1 if present and 0 if not, and the wealth index was constructed using principal component analysis (PCA). Weights were determined by factor scores derived from the first principal component in the PCA. The constructed wealth index values were then assigned to each individual based on common variables. We established cutoff values for percentiles of the population, and we classified participants into three groups: poor (bottom $40 \%$ ), middle (middle $40 \%$ ), or rich (top $20 \%$ ), following the cutoffs used in an earlier study. Place of residence was classified as rural or urban.

\section{Statistical Analysis}

In the descriptive analyses, the characteristics of the study population for selected countries were expressed as percentages (\%) with 95\% confidence interval (Cls). For independent variables, the category found to be at the least risk for having an LBW baby in the analysis was considered as the reference for constructing odds ratios (ORs). A multivariate logistic regression model was applied to estimate ORs as a measure of the associations between LBW and related risk factors after considering potential confounders. The diagnostic tests were employed in the analyses. Normality test for the birth weight data was accomplished through graphically. Goodness of fit was assessed using the Hosmer and Lemeshow statistic [25]. The variance inflation factor (VIF) test was performed to determine whether multicollinearity was present. For all the tests conducted in the study, $p<0.05$ were considered to indicate statistical significance. In the analyses, the sampling weight was adjusted based on the DHS data [26], and all statistical analyses were carried out using Stata/SE 13.0 (StataCorp, College Station, TX, USA).

\section{Ethical Approval}

Ethical clearance to conduct the DHS was obtained from the Measure DHS and the Ethics Committee of ICF Macro (Calverton, MD, USA). The DHS data are publicly accessible and were made available to us upon request by Measure DHS. 
Table 1. Distribution of birth weight for respondents' most recent pregnancy in 10 selected developing countries, with the years surveyed

\begin{tabular}{|c|c|c|c|c|c|c|c|}
\hline \multirow[b]{2}{*}{ Countries } & \multirow[b]{2}{*}{ Survey years ${ }^{1}$} & \multirow{2}{*}{$\begin{array}{c}\text { No. of live } \\
\text { births }^{2}\end{array}$} & \multicolumn{2}{|c|}{ LBW $^{3}$} & \multicolumn{2}{|c|}{ Extreme LBW ${ }^{4}$} & \multirow{2}{*}{$\begin{array}{c}\text { Overall } \\
\text { prevalence of } \\
\text { LBW }^{5}\end{array}$} \\
\hline & & & $\begin{array}{c}\text { Average } \\
\text { weight (g) }\end{array}$ & Prevalence & $\begin{array}{c}\text { Average } \\
\text { weight (g) }\end{array}$ & Prevalence & \\
\hline Armenia & 2010 & 1426 & 2214.8 & 8.4 & 1178.6 & 0.5 & 9.0 \\
\hline Cambodia & 2010 & 5929 & 2292.4 & 14.5 & 1085.0 & 0.4 & 14.2 \\
\hline Colombia & 2010 & 12029 & 2267.8 & 12.2 & 1114.6 & 1.0 & 11.8 \\
\hline Indonesia & 2012 & 15135 & 2288.7 & 12.2 & 1098.5 & 0.7 & 12.9 \\
\hline Jordan & 2012 & 9734 & 2202.2 & 19.6 & 1036.4 & 1.3 & 22.0 \\
\hline Nepal & 2011 & 1955 & 2294.4 & 27.1 & 1171.1 & 1.0 & 29.7 \\
\hline Pakistan & $2012-2013$ & 1458 & 2147.9 & 31.4 & 1079.9 & 5.8 & 35.1 \\
\hline Tanzania & 2010 & 4325 & 2285.8 & 13.0 & 1072.7 & 0.4 & 13.9 \\
\hline Uganda & 2011 & 4078 & 2231.2 & 15.8 & 1012.3 & 0.8 & 16.9 \\
\hline Zimbabwe & $2010-2011$ & 3862 & 2270.6 & 14.2 & 1039.3 & 0.8 & 14.5 \\
\hline Total & & 59932 & 2251.7 & 14.9 & 1076.9 & 1.0 & 15.9 \\
\hline
\end{tabular}

LBW, low birth weight; DHS, Demography and Health Survey.

${ }^{1}$ All data were derived from the standard DHS.

${ }^{2} \mathrm{DHS}$ sampling weight was adjusted.

${ }^{3} \mathrm{LBW}$ was defined as a birth weight between $1500 \mathrm{~g}$ and $2500 \mathrm{~g}$.

${ }^{4}$ Extreme LBW was defined as a birth weight $<1500 \mathrm{~g}$.

${ }^{5}$ The overall prevalence of LBW was defined based on an LBW definition of birth weight $<2500 \mathrm{~g}$.

\section{RESULTS}

\section{Population Characteristics}

A total of 59932 live births were recorded in the study countries (Table 1); Indonesia had the highest number (15 135 live births), followed by Colombia (12 029 live births). Birth weight data were demonstrated to be normally distributed (Figure 1). The overall prevalence of LBW was $15.9 \%(95 \% \mathrm{Cl}, 15.6$ to 16.2\%), and the average birth weight of LBW babies was 2179 $\mathrm{g}$ (Figure 2). Pakistan had the highest prevalence of LBW (35.1\%; $95 \% \mathrm{Cl}, 32.9$ to $37.3 \%$ ), followed by Nepal (29.7\%; $95 \%$ $\mathrm{Cl}, 27.7$ to $31.7 \%$ ), with average birth weights of $1988 \mathrm{~g}$ and $2255 \mathrm{~g}$, respectively (Table 1 ).

The majority of the mothers (73.5\%) were between 20 and 34 years of age, and more than half of the mothers did not have any formal education, with the highest proportion found in Pakistan (57.2\%), followed by Nepal (46.5\%) (Table 2). Overall, $52 \%$ of mothers were non-working, with the highest amount observed in Jordan (85.7\%), followed by Pakistan (74.2\%). Approximately $93.8 \%$ of mothers had taken iron pills, and more than $63 \%$ of mothers had not an acceptable level of $\mathrm{Hb}(<12.0$ $\mathrm{g} / \mathrm{dL}$ ). Overall, approximately $69.8 \%$ of mothers received adequate ANC (4 or more visits) during their last pregnancy. However, the highest percentages of adequate ANC were observed among the mothers in Armenia (94.8\%), Colombia (89.8\%), Indonesia (88.4\%), and Jordan (94.5\%). Nearly half of the mothers lived in households with a low socioeconomic status (Table 2).

\section{Factors Influencing the Determinants of Low Birth Weight}

In this study, step-up methods were used to enter all factors into a single regression model for adjusted analysis (Table 3 ). This model showed that a number of factors significantly influenced LBW. The regression model explained $22 \%$ of total variation (Cox-Snell $\left.\mathrm{R}^{2}=22 \%\right)$. The VIF test, which had a mean (maximum) value of 2.22 (4.12), indicated that no evidence of multicollinearity was present in the regression model. The Hosmer and Lemeshow statistic showed no significant difference between the model and observed data, confirming a good fit of the model to the data. Mothers with advanced age (35 to 49 years) had a significantly greater risk of delivering LBW babies than younger mothers $(p<0.01)$ (Table 3 ). Illiterate mothers (no formal education) had a higher risk of delivering LBW babies than more highly educated mothers in Armenia (OR, 1.4; 95\% $\mathrm{Cl}, 1.1$ to $2.2 ; p<0.01)$, Indonesia (OR, $2.5 ; 95 \% \mathrm{Cl}, 1.5$ to 4.4 ; $p<0.001)$, Jordan (OR, $1.6 ; 95 \% \mathrm{Cl}, 1.1$ to $2.7 ; p<0.01)$, Nepal $(\mathrm{OR}, 1.3 ; 95 \% \mathrm{Cl}, 1.1$ to $1.5 ; p<0.001)$, Pakistan (OR, 2.6; $95 \% \mathrm{Cl}$, 1.3 to $6.6 ; p<0.001)$, and Uganda (OR, $2.1 ; 95 \% \mathrm{Cl}, 1.6$ to 7.6 ; 

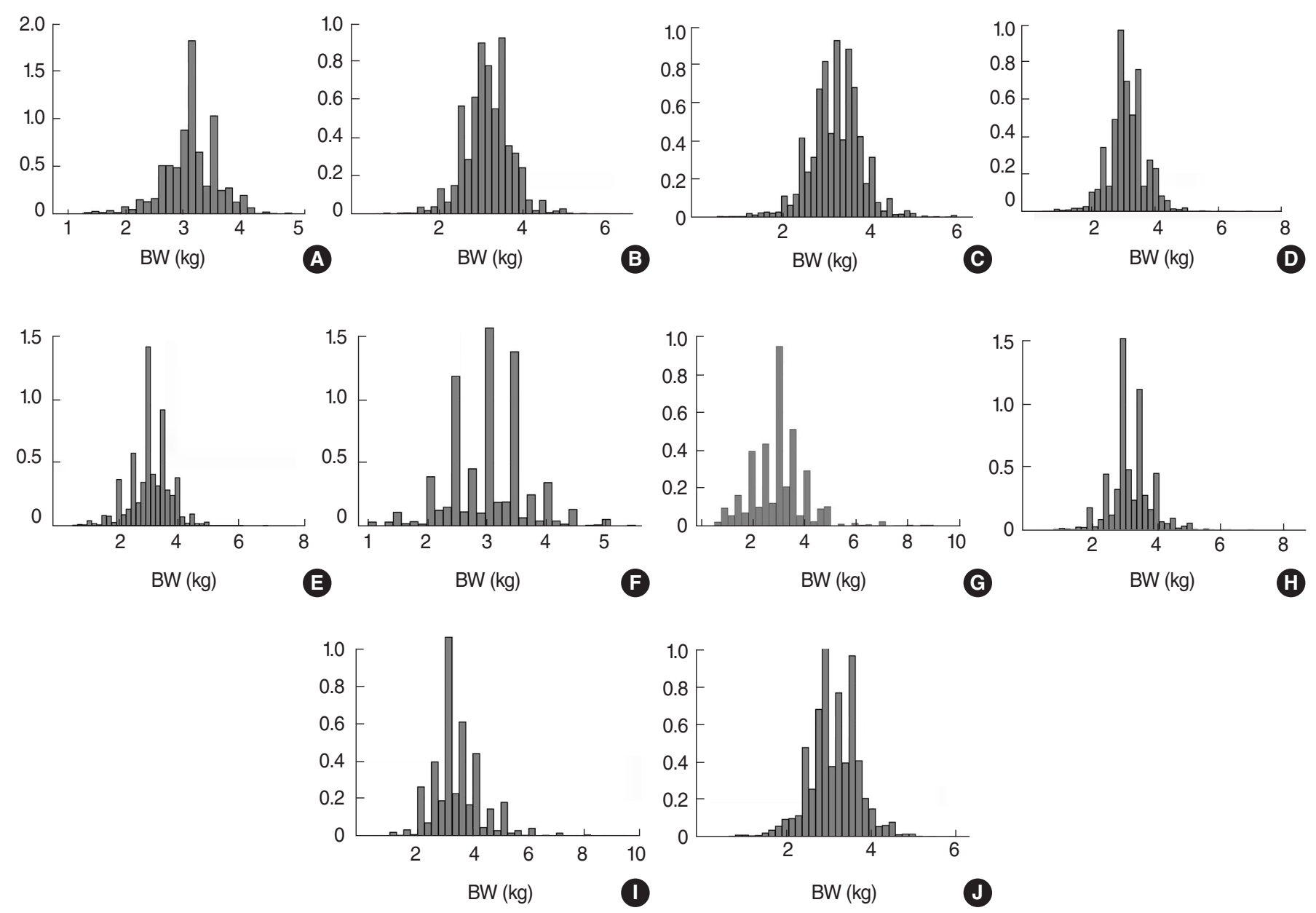

Figure 1. Distribution of birth weight (BW) for selected 10 developing countries (A) Armenia, (B) Cambodia, (C) Colombia, (D) Indonesia, (E) Jordan, (F) Nepal, (G) Pakistan, (H) Tanzania, (I) Uganda, and (J) Zimbabwe.

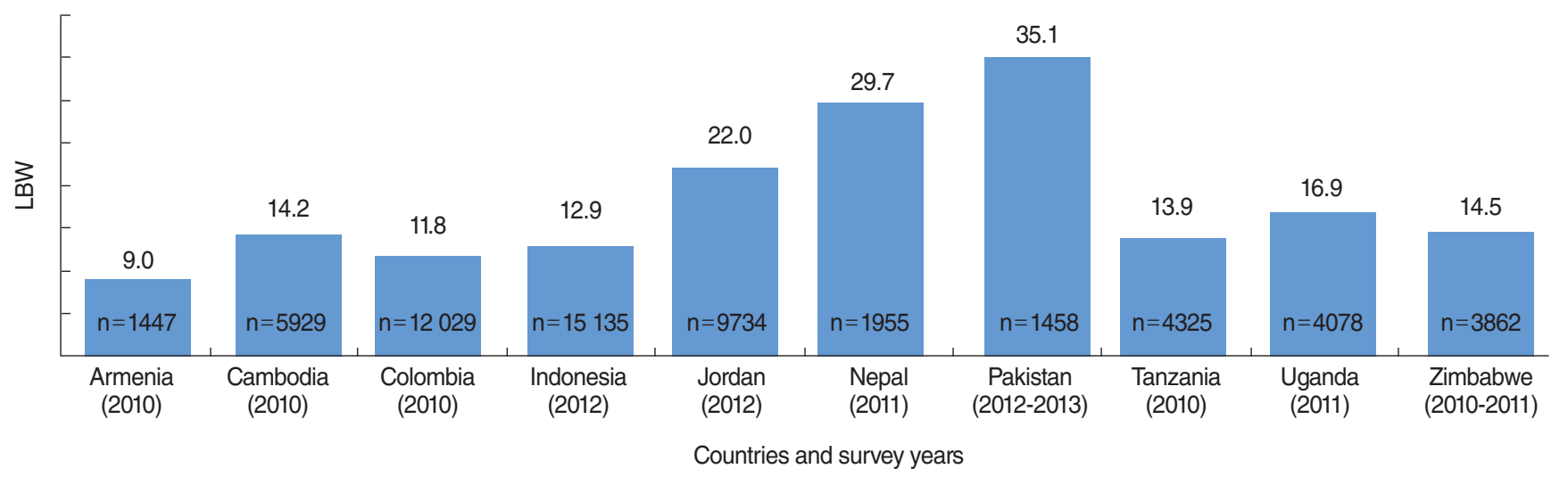

Figure 2. Prevalence of low birth weight (LBW) in developing countries.

$p<0.01)$. Female babies were more prone to have a LBW than male babies in Armenia (OR, $1.4 ; 95 \% \mathrm{Cl}, 1.1$ to $1.8 ; p<0.01)$, Cambodia (OR, 1.4; $95 \% \mathrm{Cl}, 1.1$ to $1.6 ; p<0.01)$, Colombia (OR, $1.3 ; 95 \% \mathrm{Cl}, 1.1$ to $1.5 ; p<0.001)$, Indonesia $(\mathrm{OR}, 1.2 ; 95 \% \mathrm{Cl}, 1.1$ to $1.3 ; p<0.001)$, Jordan $(\mathrm{OR}, 1.6 ; 95 \% \mathrm{Cl}, 1.3$ to $1.8 ; p<0.001)$, and Tanzania (OR, $1.4 ; 95 \% \mathrm{Cl}, 1.1$ to $1.9 ; p<0.001)$, as well as in all countries overall (OR, $1.4 ; 95 \% \mathrm{Cl}, 1.3$ to $1.6 ; p<0.001)$.

Moreover, delayed conception (over 48 months) had signifi- 


\section{Journal of}

Table 2. Distribution of background characteristics in the study population from 10 selected developing countries ${ }^{1}$

\begin{tabular}{|c|c|c|c|c|c|c|}
\hline \multirow{2}{*}{ Background characteristics } & \multicolumn{6}{|c|}{ Countries } \\
\hline & Armenia & Cambodia & Colombia & Indonesia & Jordan & Nepal \\
\hline \multicolumn{7}{|l|}{ Maternal age (y) } \\
\hline $20-34$ & $89.0(86.8,91.0)$ & $76.5(75.3,77.6)$ & $72.4(71.5,73.2)$ & $71.4(70.5,72.4)$ & $69.5(68.0,71.0)$ & $81.3(80.0,82.5)$ \\
\hline $35-49$ & $8.8(7.0,10.9)$ & $20.9(19.7,22.1)$ & $17.2(16.5,18.0)$ & $25.6(24.7,26.6)$ & $28.7(27.2,30.2)$ & $11.7(10.7,12.7)$ \\
\hline \multicolumn{7}{|l|}{ Maternal height (cm) } \\
\hline Tall $(>155)$ & & $35.4(33.7,37.1)$ & $59.4(58.5,60.3)$ & & $73.9(72.8,75)$ & $27.8(25.0,30.7)$ \\
\hline \multicolumn{7}{|l|}{ Sex of child } \\
\hline Male & $51.8(49.2,54.4)$ & $51.5(50.2,52.8)$ & $51.7(50.8,52.6)$ & $50.9(50.1,51.7)$ & $52.1(51.1,53.1)$ & $51.6(49.4,53.8)$ \\
\hline Female & $48.2(45.6,50.8)$ & $48.5(47.2,49.8)$ & $48.3(47.4,49.2)$ & $49.1(48.3,49.9)$ & $47.9(46.9,48.9)$ & $48.4(46.2,50.6)$ \\
\hline \multicolumn{7}{|l|}{ Maternal education } \\
\hline Not working & $84.9(82.6,87.0)$ & $33.5(32.2,34.8)$ & $54.4(53.5,55.4)$ & $52.3(51.2,53.3)$ & $85.7(84.6,86.8)$ & $45.1(43.4,46.7)$ \\
\hline Working & $15.1(13.0,17.4)$ & $66.5(65.2,67.8)$ & $45.6(44.6,46.5)$ & $47.8(46.7,48.8)$ & $14.3(13.2,15.4)$ & $54.9(53.3,56.6)$ \\
\hline \multicolumn{7}{|l|}{ Marriage to first birth interval (mo) } \\
\hline First birth & $54.6(51.3,57.8)$ & $35.6(34.3,36.9)$ & $44.6(43.5,45.8)$ & $46.9(45.8,47.9)$ & $49.5(47.8,51.1)$ & $24.4(23.0,25.9)$ \\
\hline$<24$ & $32.0(29.2,35.0)$ & $35.7(34.3,37.0)$ & $24.9(24.0,25.9)$ & $31.4(30.4,32.4)$ & $31.7(30.2,33.3)$ & $32.3(30.8,33.9)$ \\
\hline $24-47$ & $11.2(9.2,13.5)$ & $22.2(21.1,23.4)$ & $20.6(19.7,21.6)$ & $15.9(15.1,16.75)$ & $14.2(13.1,15.4)$ & $28.9(27.5,30.5)$ \\
\hline$\geq 48$ & $2.3(1.5,3.3)$ & $6.5(5.9,7.2)$ & $9.8(9.1,10.5)$ & $5.8(5.3,6.4)$ & $4.6(4.0,5.4)$ & $14.3(13.2,15.5)$ \\
\hline \multicolumn{7}{|l|}{ Parity } \\
\hline First child & $47.2(44.6,49.8)$ & $38.4(37.2,39.6)$ & $44.0(43.1,44.9)$ & $40.0(39.2,40.8)$ & $23.4(22.6,24.3)$ & $50.6(48.4,52.8)$ \\
\hline $2-3$ & $49.6(47.0,52.2)$ & $43.2(41.9,44.4)$ & $44.8(43.9,45.6)$ & $47.2(46.4,48.0)$ & $39.0(38.1,40.0)$ & $40.4(38.2,42.6)$ \\
\hline Inadequate (0 or 1$)$ & $1.2(0.6,2.9)$ & $15.2(13.7,16.8)$ & $3.9(2.8,4.5)$ & $4.7(3.6,6.8)$ & $1.5(1.0,2.4)$ & $21.2(18.6,25.3)$ \\
\hline Intermediate (2 or 3 ) & $4.0(2.6,6.5)$ & $25.2(23.3,27.2)$ & $6.3(4.6,7.0)$ & $6.9(5.6,8.5)$ & $4.0(3.0,5.3)$ & $28.7(26.0,31.4)$ \\
\hline Adequate (4 or more) & $94.8(93.0,96.1)$ & $59.6(58.2,61.1)$ & $89.8(89.1,90.4)$ & $88.4(87.8,89.1)$ & $94.5(93.5,95.4)$ & $50.1(48.2,52.0)$ \\
\hline \multicolumn{7}{|l|}{ Place of delivery } \\
\hline Facility & $99.9(99.5,100)$ & $72.7(71.2,74.1)$ & $98.6(98.3,98.8)$ & $70.2(69.2,71.2)$ & $99(98.6,99.3)$ & $35.3(29.5,45.6)$ \\
\hline Home & $0.1(0.0,0.5)$ & $27.3(25.9,28.8)$ & $1.4(1.2,1.7)$ & $29.8(28.8,30.8)$ & $1(0.7,1.6)$ & $64.7(51.9,71.9)$ \\
\hline \multicolumn{7}{|l|}{ Nutritional status } \\
\hline Low BMI & & $15.6(14.3,17.0)$ & $3.8(3.5,4.2)$ & & $2.1(1.5,2.8)$ & $19.5(17.6,21.5)$ \\
\hline Normal BMI & NA & $72.7(71.1,74.3)$ & $49.7(48.8,50.6)$ & NA & $32.8(30.8,34.7)$ & $71.0(68.7,73.1)$ \\
\hline Overweight & & $11.7(10.6,12.9)$ & $46.5(45.6,47.4)$ & & $65.2(63.2,67.1)$ & $9.5(8.2,11.0)$ \\
\hline \multicolumn{7}{|l|}{ Wealth status } \\
\hline Poor (lower 40\%) & $40.8(37.7,43.9)$ & $48.1(46.8,49.5)$ & $48.2(47.3,49.2)$ & $41.2(40.2,42.2)$ & $45.5(43.9,47.1)$ & $47.7(46.1,49.3)$ \\
\hline Middle (middle 40\%) & $40.5(37.3,43.7)$ & $35.5(34.2,36.8)$ & $39.8(38.8,40.8)$ & $39.8(38.8,40.9)$ & $40.8(39.2,42.4)$ & $38.4(36.8,40.1)$ \\
\hline Rich (upper 20\%) & $18.7(16.0,21.8)$ & $16.4(15.5,17.4)$ & $12.0(11.3,12.7)$ & $19.0(18.1,19.9)$ & $13.8(12.4,15.3)$ & $13.9(12.8,15.0)$ \\
\hline \multicolumn{7}{|l|}{ Place of residence } \\
\hline Urban & $58.4(55.23,61.5)$ & $15.6(14.8,16.5)$ & $72.0(71.1,72.8)$ & $49.6(48.5,50.7)$ & $81.46(80.5,82.4)$ & $9.3(8.7,10.0)$ \\
\hline Rural & $41.6(38.5,44.8)$ & $84.4(83.5,85.2)$ & $28.0(27.2,28.9)$ & $50.4(49.3,51.5)$ & $18.5(17.7,19.5)$ & $90.7(90.0,91.3)$ \\
\hline Total (n) & 1426 & 5929 & 12029 & 15135 & 9734 & 1955 \\
\hline
\end{tabular}


Table 2. Continued from the previous page

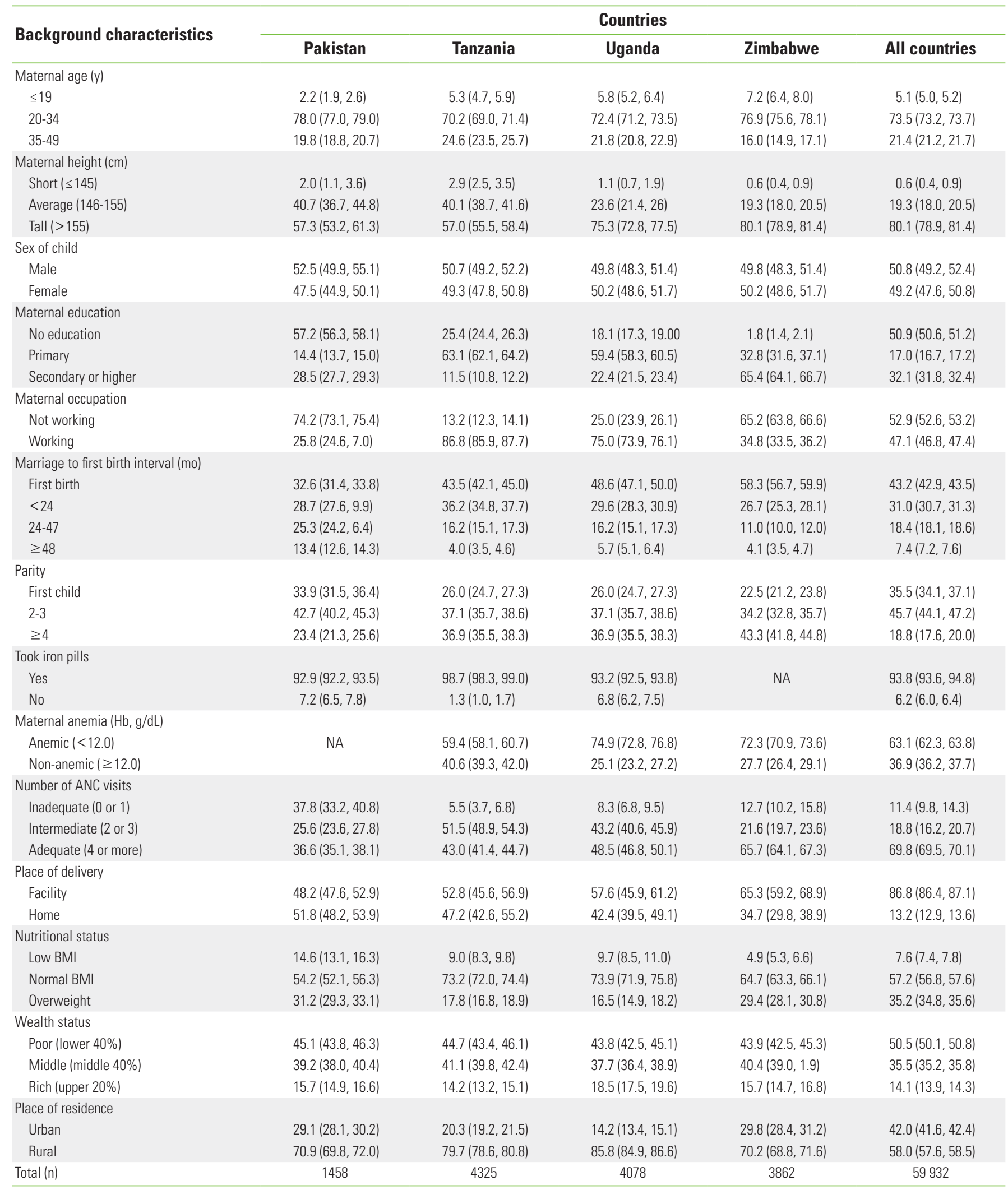

Values are presented as \% (95\% confidence interval).

DHS, Demography and Health Survey; NA, not available; BMI, body mass index; Hb, hemoglobin; ANC, antenatal care.

'DHS sampling weight adjusted. 


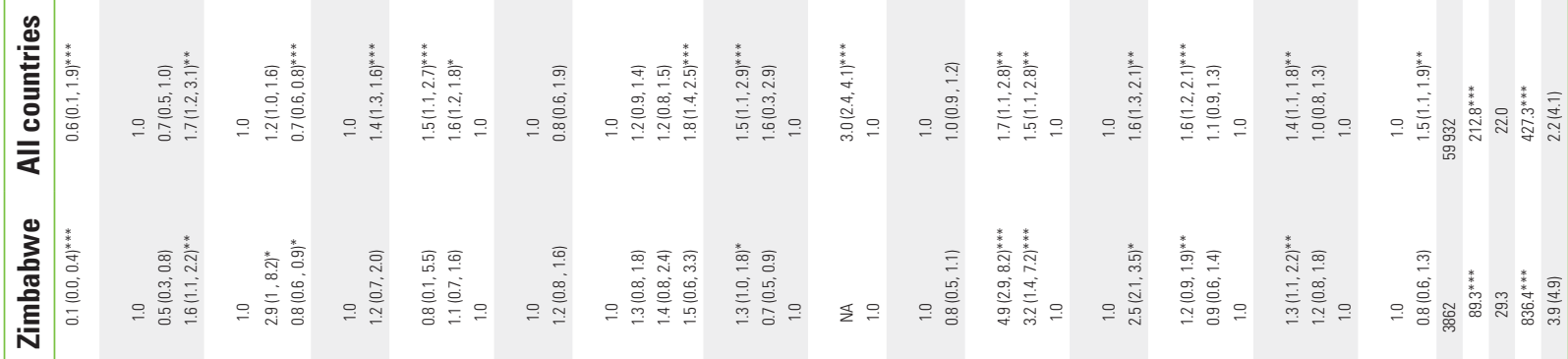

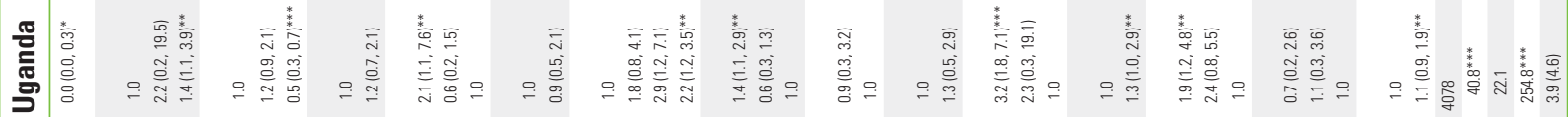

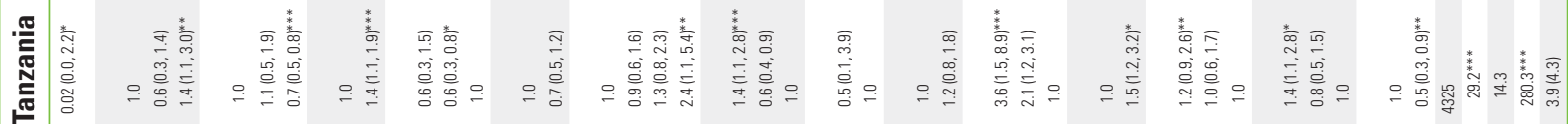

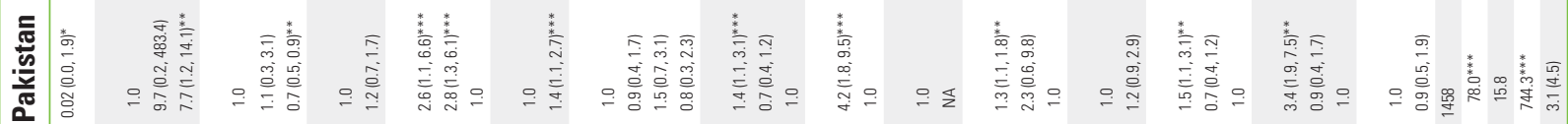

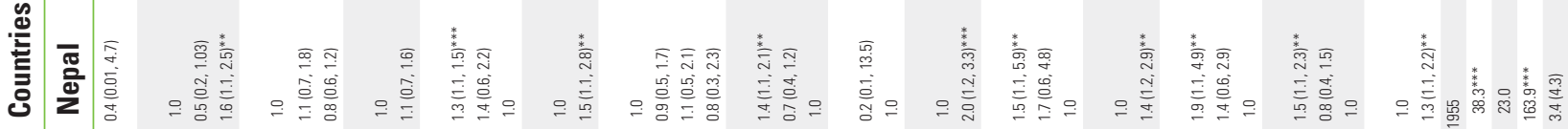

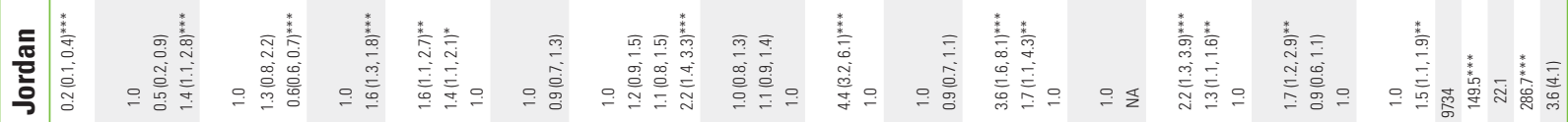

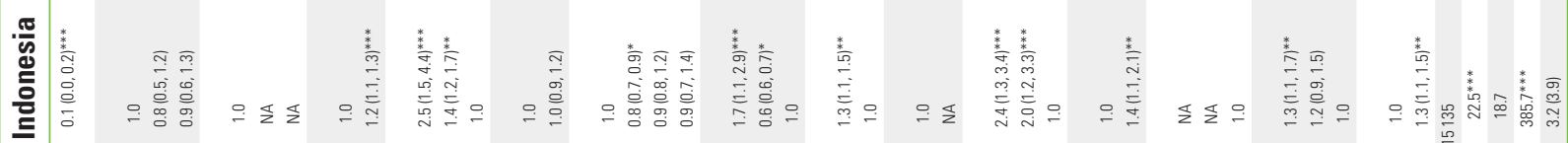

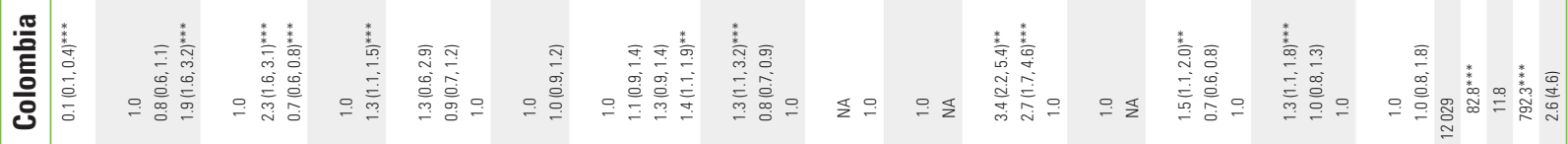

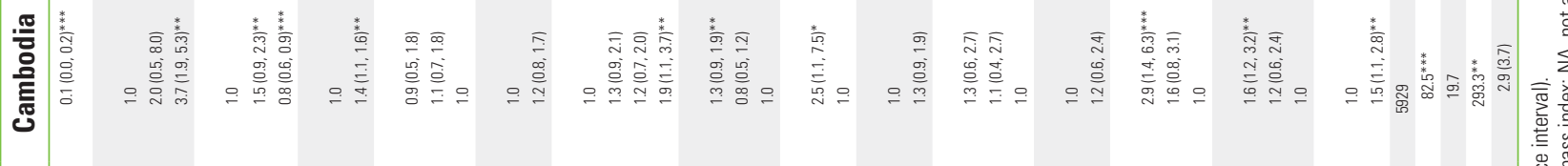

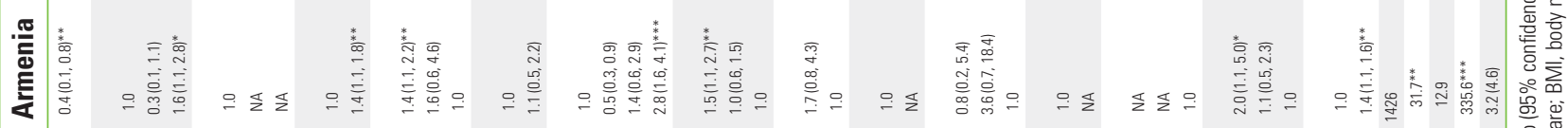
兽

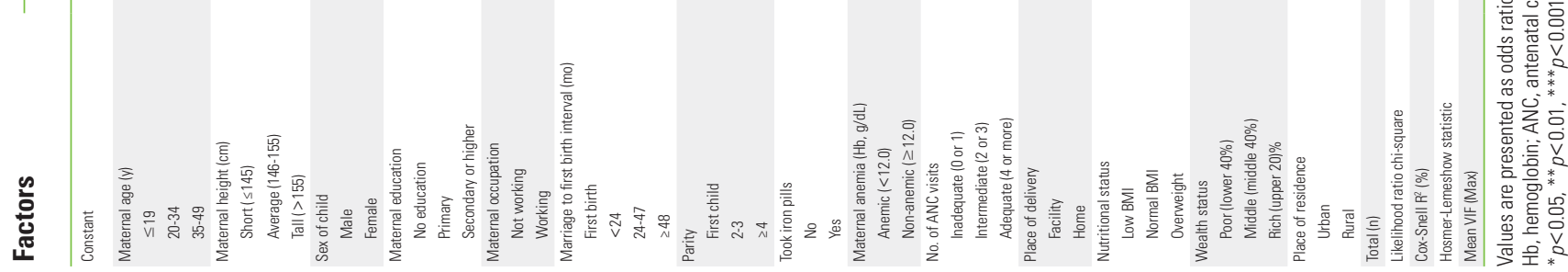


cant relationship with LBW in Armenia (OR, 2.8; $95 \% \mathrm{Cl}, 1.6$ to $4.1 ; p<0.01)$, Cambodia (OR, 1.9; $95 \% \mathrm{Cl}, 1.1$ to $3.7 ; p<0.01$ ), Colombia (OR, 1.4; $95 \% \mathrm{Cl}, 1.1$ to $1.9 ; p<0.01)$, Jordan (OR, 2.2; $95 \% \mathrm{Cl}, 1.4$ to $3.3 ; p<0.001)$, Tanzania (OR, $2.4 ; 95 \% \mathrm{Cl}, 1.1$ to $5.4 ; p<0.01)$, and Uganda (OR, $2.2 ; 95 \% \mathrm{Cl}, 1.2$ to $3.5 ; p<0.001)$. In all countries, ANC visits were associated with significant reductions in LBW, while receiving inadequate ANC was associated with an elevated risk of LBW (OR, 1.7; 95\% Cl, 1.1 to 2.8; $p<0.01$ ). In addition, in most of the countries, we observed a significantly increased risk of LBW in newborns born to mothers with certain specific characteristics, such as low BMI (OR, $1.6 ; 95 \% \mathrm{Cl}, 1.2$ to $2.1 ; p<0.001$ ) (with normal weight as the reference), primiparity (OR, $1.5 ; 95 \% \mathrm{Cl}, 1.1$ to $2.9 ; p<0.001)$ (with parity of 4 or above as the reference), residing in rural communities (OR, $1.5 ; 95 \% \mathrm{Cl}, 1.1$ to $1.9 ; p<0.001)$, as well as lower wealth status of households (OR, $1.4 ; 95 \% \mathrm{Cl}, 1.2$ to 1.8 ; $p<0.001$ ) in comparison with the rich group.

\section{DISCUSSION}

In this study, we identified potential determinants of the prevalence of LBW in developing countries. Our findings demonstrated that advanced maternal age (35 to 49 years), lack of ANC, primiparity, illiteracy, later conception, and being in the poorest socioeconomic stratum were significantly associated with LBW. Previous studies have likewise found that women with advanced maternal age are more likely to give birth to LBW babies [1,2,27-29]. Pregnant women aged $\geq 35$ years are more likely to increase the probability of risk having pregnancy complications compared with younger women, like as, gestational diabetes, placenta praevia, breech presentation, that might be cause of delivering babies with LBW. Women with poor educational status were generally at a higher risk of having an LBW baby than mothers with secondary or higher education. These findings are consistent with those of some previous studies conducted in developing countries [1,30-32]. We found that later conception was associated with a significantly greater risk of LBW. This may be related to age, because increased age is related to common chronic diseases such as arthritis, hypertension, and diabetes prior to pregnancy [27]. However, these findings are in contrast with those of another study conducted in a developing country [31]. The present study also observed an increased risk of LBW among newborns born to mothers with a low BMI in comparison to normalweight mothers. This finding parallels those of earlier studies conducted in low-middle income countries showing that infants of low-BMI mothers had a significantly higher likelihood of LBW [31,33-36]. Additionally, low socioeconomic status was a risk factor of $L B W$, confirming the findings of previous studies that the poorest women in developing countries are at a significantly higher risk of delivering LBW infants [32,37].

The present study found that receiving insufficient ANC was a significant contributor to LBW. Specifically, in women who failed to receive any ANC or had inadequate ANC than recommended, the risk of $L B W$ was higher than in women attending the standard number of ANC visits [38]. Similar results have also been reported in previous studies conducted in developing countries, although the magnitude of risk appears to vary substantially in different settings depending on the ANC system and the degree of attendance $[28,31,35,39]$. Comparing our findings to those of prior studies, the evidence suggests that the degree of risk may be diluted in settings with a standard frequency of ANC. Women living in rural communities had a greater risk of LBW than urban mothers. Similar results have been found in other studies [1,2,6,35]. Although this study has some strength, such as the large sample size and quality of data, it also has important limitations. The selected countries were found to have a large amount of missing birth weight data. They were also selected to ensure geographical coverage of less developed regions as well as based on the presence of available data related to the study variables. The reported number of home deliveries may have been influenced by social, cultural, and economic factors, and is likely to be country-specific and region-specific, as well as to change over time, and these possibilities were not captured in this analysis. Moreover, the selected DHSs were conducted in different years, which may have resulted in inconsistencies. A high percentage of babies delivered at home had inadequate birth weight measurements, with a large proportion of missing data. Consequently, many samples were excluded from the study. The aggregation of country data into regional summaries by wealth quintile may have caused errors through the combination of wealth quintiles from countries at differing wealth levels. Additional multilevel analysis of existing datasets could provide more detailed information for individual countries on adverse pregnancy outcomes as well as on health-seeking behavior related to maternal and child health.

In summary, this study identified some significant risk factors with independent effects on the prevalence of LBW in selected developing countries. Among these factors, inadequate 
ANC, delayed conception, and maternal age had a greater potential effect on birth weight. Improvements in these specific risk factors might have the positive effect in reducing the incidence of LBW. However, interventions to improve the educational levels of women and female children are also important for reducing the prevalence of LBW. Different strategies should be implemented considering the settings of individual countries, with appropriate community-based interventions focusing on these factors so that policy-makers can design effective plans for improving overall maternal and child health in selected developing countries.

\section{ACKNOWLEDGEMENTS}

The International Centre for Diarrhoeal Disease Research, Bangladesh (icddr,b) gratefully acknowledges the donors who provide unrestricted support: the Government of the People's Republic of Bangladesh; Global Affairs Canada (GAC); Swedish International Development Cooperation Agency (Sida) and the Department for International Development (UK Aid). We gratefully acknowledge these donors for their support and commitment to icddr,b's research efforts. The authors would also like to thank the Measure DHS program for providing access to the data used in the study.

\section{CONFLICT OF INTEREST}

The authors have no conflicts of interest associated with the material presented in this paper.

\section{ORCID}

Rashidul Alam Mahumud http://orcid.org/0000-0001-97881868

Marufa Sultana http://orcid.org/0000-0002-4481-0748

Abdur Razzaque Sarker http://orcid.org/0000-0002-20227590

\section{REFERENCES}

1. Rezende Chrisman J, Mattos IE, Koifman RJ, Koifman S, Moraes Mello Boccolini P, Meyer A. Prevalence of very low birthweight, malformation, and low Apgar score among newborns in Brazil according to maternal urban or rural residence at birth. J Obstet Gynaecol Res 2016;42(5):496-504.
2. Assefa N, Berhane $Y$, Worku A. Wealth status, mid upper arm circumference (MUAC) and antenatal care (ANC) are determinants for low birth weight in Kersa, Ethiopia. PLoS One 2012;7 (6):e39957.

3. Brämer GR. International statistical classification of diseases and related health problems. Tenth revision. World Health Stat Q 1988;41(1):32-36.

4. Sachdev HP. Low birth weight in South Asia. Int J Diabetes Dev Ctries 2001;21(1):13-31.

5. Yadav DK, Chaudhary U, Shrestha N. Risk factors associated with low birth weight. J Nepal Health Res Counc 2011;9(19): 159-164.

6. Metgud CS, Naik VA, Mallapur MD. Factors affecting birth weight of a newborn--a community based study in rural Karnataka, India. PLoS One 2012;7(7):e40040.

7. Lau C, Ambalavanan N, Chakraborty H, Wingate MS, Carlo WA. Extremely low birth weight and infant mortality rates in the United States. Pediatrics 2013;131(5):855-860.

8. Nose S, Sasaki T, Saka R, Minagawa K, Okuyama H. A sutureless technique using cyanoacrylate adhesives when creating a stoma for extremely low birth weight infants. Springerplus 2016;5:189.

9. Canadian Institute for Health Information. Giving birth in Canada: the costs. Ottawa: Canadian Institute for Health Information; 2006, p. 1-62.

10. Hodek JM, von der Schulenburg JM, Mittendorf T. Measuring economic consequences of preterm birth: methodological recommendations for the evaluation of personal burden on children and their caregivers. Health Econ Rev 2011;1(1):6.

11. Barker DJ, Forsén T, Uutela A, Osmond C, Eriksson JG. Size at birth and resilience to effects of poor living conditions in adult life: longitudinal study. BMJ 2001;323(7324):1273-1276.

12. Martinson ML, Reichman NE. Socioeconomic inequalities in low birth weight in the United States, the United Kingdom, Canada, and Australia. Am J Public Health 2016;106(4):748754.

13. Kalanda B, Verhoeff F, le Cessie S, Brabin J. Low birth weight and fetal anaemia as risk factors for infant morbidity in rural Malawi. Malawi Med J 2009;21(2):69-74.

14. Dasgupta A, Basu R. Determinants of low birth weight in a Block of Hooghly, West Bengal: a multivariate analysis. Int J Biol Med Res 2011;2(4):838-842.

15. Deshpande JD, Phalke DB, Bangal VB, Peeyuusha D, Sushen B. Maternal risk factors for low birth weight neonates: a hospital based case control study in rural area of western maharashtra, 
India. Natl J Community Med 2011;2(3):394-398.

16. Boerma JT, Weinstein KI, Rutstein SO, Sommerfelt AE. Data on birth weight in developing countries: can surveys help? Bull World Health Organ 1996;74(2):209-216.

17. ICF International. Survey organization manual for demographic and health surveys; 2012 [cited 2016 Dec 30]. Available from: http://dhsprogram.com/pubs/pdf/DHSM10/ DHS6_Survey_Org_Manual_7Dec2012_DHSM10.pdf.

18. Channon AA, Padmadas SS, McDonald JW. Measuring birth weight in developing countries: does the method of reporting in retrospective surveys matter? Matern Child Health J 2011;15(1):12-18.

19. Robles A, Goldman N. Can accurate data on birthweight be obtained from health interview surveys? Int J Epidemiol 1999; 28(5):925-931.

20. Blanc AK, Wardlaw T. Monitoring low birth weight: an evaluation of international estimates and an updated estimation procedure. Bull World Health Organ 2005;83(3):178-185.

21. ORC Macro. DHS and World Bank use wealth index to measure socioeconomic status. DHS Dimens 2002;4(2):1-2.

22. Hazarika I. Factors that determine the use of skilled care during delivery in India: implications for achievement of MDG-5 targets. Matern Child Health J 2011;15(8):1381-1388.

23. West BT. Statistical and methodological issues in the analysis of complex sample survey data: practical guidance for trauma researchers. J Trauma Stress 2008;21(5):440-447.

24. Titaley CR, Dibley MJ, Agho K, Roberts CL, Hall J. Determinants of neonatal mortality in Indonesia. BMC Public Health 2008; $8: 232$.

25. Hosmer DW, Lemeshow S. Applied logistic regression. 2nd ed. New York: Wiley; 2000, p. 1-383.

26. Rutstein SO, Rojas G. Guide to DHS statistics: demographic and health surveys methodology; 2006 [cited 2017 Jan 18]. Available from: http://www.dhsprogram.com/pubs/pdf/ DHSG1/Guide_to_DHS_Statistics_290ct2012_DHSG1.pdf.

27. Dietl A, Cupisti S, Beckmann MW, Schwab M, Zollner U. Pregnancy and obstetrical outcomes in women over 40 years of age. Geburtshilfe Frauenheilkd 2015;75(8):827-832.

28. Isiugo-Abanihe UC, Oke OA. Maternal and environmental factors influencing infant birth weight in Ibadan, Nigeria. Afr Popul Stud 2011;25(2):250-266.
29. Nobile CG, Raffaele G, Altomare C, Pavia M. Influence of maternal and social factors as predictors of low birth weight in Italy. BMC Public Health 2007;7:192.

30. Muthayya S. Maternal nutrition \& low birth weight - what is really important? Indian J Med Res 2009;130(5):600-608.

31. Khatun S, Rahman M. Socio-economic determinants of low birth weight in Bangladesh: a multivariate approach. Bangladesh Med Res Counc Bull 2008;34(3):81-86.

32. Sebayang SK, Dibley MJ, Kelly PJ, Shankar AV, Shankar AH; SUMMIT Study Group. Determinants of low birthweight, small-for-gestational-age and preterm birth in Lombok, Indonesia: analyses of the birthweight cohort of the SUMMIT trial. Trop Med Int Health 2012;17(8):938-950.

33. Euser AM, Finken MJ, Keijzer-Veen MG, Hille ET, Wit JM, Dekker FW, et al. Associations between prenatal and infancy weight gain and BMI, fat mass, and fat distribution in young adulthood: a prospective cohort study in males and females born very preterm. Am J Clin Nutr 2005;81(2):480-487.

34. Yazdanpanahi Z, Forouhari S, Parsanezhad ME. Prepregnancy body mass index and gestational weight gain and their association with some pregnancy outcomes. Iran Red Crescent Med J 2008;10(4):326-331.

35. Kayode GA, Amoakoh-Coleman M, Agyepong IA, Ansah E, Grobbee DE, Klipstein-Grobusch K. Contextual risk factors for low birth weight: a multilevel analysis. PLoS One 2014;9(10): e109333.

36. Ronnenberg AG, Wang X, Xing H, Chen C, Chen D, Guang W, et al. Low preconception body mass index is associated with birth outcome in a prospective cohort of Chinese women. J Nutr 2003;133(11):3449-3455.

37. Olsén $P$, Vainionpää L, Pääkkö E, Korkman $M$, Pyhtinen J, Järvelin MR. Psychological findings in preterm children related to neurologic status and magnetic resonance imaging. Pediatrics 1998;102(2 Pt 1):329-336.

38. Tellapragada C, Eshwara VK, Bhat P, Acharya S, Kamath A, Bhat $S$, et al. Risk factors for preterm birth and low birth weight among pregnant Indian women: a hospital-based prospective study. J Prev Med Public Health 2016;49(3):165-175.

39. Raatikainen K, Heiskanen N, Heinonen S. Under-attending free antenatal care is associated with adverse pregnancy outcomes. BMC Public Health 2007;7:268. 